\title{
Proposal of a new method for evaluating the frictional properties of tissue engineered cartilage
}

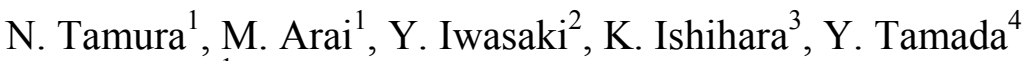 \\ \& N. Tomita ${ }^{1}$ \\ ${ }^{I}$ Graduate School of Engineering, Kyoto University, Japan \\ ${ }^{2}$ Faculty of Chemistry, Materials and Bioengineering, \\ Kansai University, Japan \\ ${ }^{3}$ School of Engineering, The University of Tokyo, Japan \\ ${ }^{4}$ National Institute of Agrobiological Sciences, Japan
}

\begin{abstract}
It is essential to investigate the tribological maturation of tissue engineered cartilage that is to be used in medical applications. The friction properties of tissue engineered cartilage have been measured using flat counter surfaces such as stainless steel, glass or ceramics. However, the measured friction properties were significantly inferior to those of natural cartilage, likely because of cartilage adhesion to the counter surface. In this study, a poly(2-methacryloyloxyethyl phosphorylcholine (MPC)) grafted surface is proposed as an appropriate counter surface for cartilage friction evaluation due to the material's ability to reduce the adhesion and reproduce natural tribological conditions. The poly(MPC) grafted surfaces were prepared by atom transfer radical polymerization (ATRP). The friction coefficients for natural cartilage that were measured on the poly(MPC) grafted surface were lower than 0.01 at the sliding velocities of 0.08 and $0.008 \mathrm{~mm} / \mathrm{s}$, which is equivalent to that for natural cartilage-on-cartilage. The friction coefficients for the tissue engineered cartilage were reduced with cultivation time at low sliding velocities. Thus it is suggested that the proposed system is able to measure the tribological maturation of tissue engineered cartilage in a more natural lubricating environment.

Keywords: tribological maturation, tissue engineered cartilage, cartilage adhesion, poly(MPC) grafted surface, natural tribological condition, ATR, natural cartilage, friction coefficient, sliding velocity, cultivation time.
\end{abstract}




\section{Introduction}

Recently, transplantation of tissue engineered cartilage for the medical treatment of osteoarthritis has attracted a great deal of attention. It is essential to evaluate the biochemical and mechanical maturation of tissue engineered cartilage in order to determine an appropriate post-transplantation schedule. Many studies have reported on the amount of synthesized extracellular matrix or the material values of tissue engineered cartilage [3-6]. However, the tribological properties of tissue engineered cartilage have rarely been discussed. Morita et al. measured the friction coefficients of tissue engineered cartilage by using a reciprocatingmotion friction testing apparatus [1]. However, the measured friction coefficients for all culture times were much higher than those reported for in vivo measurements. It seems probable that tissue engineered cartilage adhered onto the counter surface, increasing the adhesive force between the tissue and stainless steel. In order to evaluate frictional behavior of tissue engineered cartilage accurately, it is necessary to do so under in vivo like conditions.

In this study, a poly(2-methacryloyloxyethyl phosphorylcholine (MPC)) grafted surface was proposed for use as a counter surface in a reciprocatingmotion friction test and used to accurately measure the friction coefficients of tissue engineered cartilage.

\section{Materials and methods}

\subsection{Preparation of counter surface}

\subsubsection{Poly(MPC) grafted counter surface}

The MPC was synthesized by previously reported methods [7]. The poly(MPC) grafted surface was prepared by surface-initiated atom transfer radical polymerization (ATRP) on silicon wafers [8]. The average thickness of the silicon wafers used was $580 \mu \mathrm{m}$, with disks cut into $1.4 \times 1.4 \mathrm{~cm}$ pieces. The $3-(2-$ Bromoisobutyryl)propyl dimethylchlorosilane (BDCS) was synthesized as previously described $[8,9]$. The BDCS monolayer on the silicon wafer, which was used as an initiator for ATRP, was prepared as previously reported [9]. Silicon wafers were ozonized using a plasma-reactor apparatus (Yamato scientific Co. Ltd., Tokyo, Japan) and held in a custom-designed holder and submerged in $30 \mathrm{~mL}$ of dry toluene and BDCS $(33 \mu \mathrm{L}, 0.15 \mathrm{~mol})$ with in a glass tube and purged with argon gas for $30 \mathrm{~min}$. The glass tube was allowed to stand overnight and wrapped in aluminium foil to prevent exposure to light. The wafers were then removed from the solution, rinsed sequentially with toluene, 2propanol, absolute ethanol, 50\% ethanol and pure water, and dried in nitrogen gas. Copper bromide (I) (29 mg, 0.20 mmol, Sigma-Aldrich Co. LLC., St. Louis, MO), 2,2'-Bipyridyl (63 mg, $0.40 \mathrm{mmol}$, Sigma-Aldrich) and $12 \mathrm{~mL}$ of deoxygenated methanol were introduced into the glass tube with a stopcock. Then ethyl-2-bromoisobutyrate $(30.4 \mu \mathrm{L}, 0.20 \mathrm{mmol}$, Sigma-Aldrich) was added as a sacrificial initiator. After being purged with argon gas for $30 \mathrm{~min}$, the BDCS-immobilized silicon wafers were then submerged into the solution. 
A $21 \mathrm{~mL}$ solution of methanol containing the MPC powder (12 g, $0.04 \mathrm{~mol})$ was also purged with argon gas for $30 \mathrm{~min}$ and then added into the glass tube. Polymerization was then allowed to occur for 3 hours at room temperature with stirring in argon gas atmosphere. The thickness of the poly(MPC) brush-type graft layer was $8 \mathrm{~nm}$ and the density of the poly(MPC) chains was 0.21 chains $/ \mathrm{nm}^{2}$. Before the friction test, the poly(MPC) grafted counter surface was rinsed with a $50 \%(\mathrm{v} / \mathrm{v})$ isopropanol and distilled water solution.

\subsubsection{Stainless steel surface}

A stainless steel surface was used as a control group for the poly(MPC) grafted counter surfaces. The surface roughness of stainless steel (SUS304) was approximately $0.06 \mu \mathrm{m} \mathrm{Ra}$. Before the friction test, the stainless steel surface was washed with $50 \%(\mathrm{v} / \mathrm{v})$ isopropanol for $10 \mathrm{~min}$ in an ultrasonic cleaner.

\subsection{Preparation of the scaffold for cultivation}

We used a fibroin sponge as a scaffold. The fibroin sponges were prepared as described previously [10-13]. Silk threads degummed from silk cocoons were dissolved in $9.0 \mathrm{~mol} / \mathrm{L}$ lithium bromide, dialyzed with water purified through reverse osmosis. The fibroin protein solution, to which a water-soluble organic solvent $(1.0 \%(\mathrm{v} / \mathrm{v})$ dimethyl sulfoxide) was added, was frozen for 12 hours at $-20^{\circ} \mathrm{C}$ and then thawed at room temperature to form a sponge-like material. The average pore diameter in the sponge was $80 \mu \mathrm{m}$. After autoclave sterilization $\left(121^{\circ} \mathrm{C}\right.$ for $\left.20 \mathrm{~min}\right)$, the fibroin sponges were preserved in $\mathrm{PBS}$ at $4^{\circ} \mathrm{C}$ until chondrocyte seeding.

\subsection{Preparation of chondrocytes}

A chondrocyte suspension was prepared as described previously [10-14]. Articular cartilage tissue was taken from the proximal humerus, distal femur and proximal tibia of 4-week-old Japanese white rabbits (Oriental Bio Service, Inc., Kyoto, Japan) and preserved in Dulbecco's modified Eagle medium (DMEM) (Nacalai Tesque, Inc., Kyoto, Japan) containing 10\% (v/v) FBS, 1\% (v/v) antibiotic and $0.2 \mathrm{mM}$ ascorbic acid (A8960, Sigma-Aldrich). Chondrocytes were then isolated via enzymatic digestion as described as follows. After being rinsed twice with $\mathrm{PBS}$, the cartilage slices were digested for $30 \mathrm{~min}$ at $37^{\circ} \mathrm{C}$ with a $0.25 \%$-Trypsin/1 mM-EDTA solution (Nacalai Tesque). After that, the tissues were rinsed twice with PBS and digested with $0.25 \%$ collagenase (Worthington Biochemical Corporation, New Jersey, USA) for 6 hours at $37^{\circ} \mathrm{C}$. After digestion of the collagen fibre, chondrocytes were isolated using a Cell Strainer (BD falcon, New Jersey, USA), rinsed twice with PBS, suspended in Cell Banker (Nippon Zenyaku Kogyo Co., Ltd., Fukushima, Japan) and preserved at $-80^{\circ} \mathrm{C}$.

\subsection{Preparation of tissue engineered cartilage specimens}

Tissue engineered cartilage specimens were prepared as described previously [1-3]. Fibroin sponges were cut into disks that were $8.0 \mathrm{~mm}$ in diameter and 
$1.0 \pm 0.2 \mathrm{~mm}$ in thickness, and incubated with DMEM at $37^{\circ} \mathrm{C}$ in a humidified atmosphere of $95 \%$ air and $5 \% \mathrm{CO}_{2}$ for 3 hours. The chondrocytes were cultured first in a T-flask (Asahi glass Co., Ltd., Tokyo, Japan) with DMEM at $37^{\circ} \mathrm{C}$ in a humidified atmosphere of $95 \%$ air and $5 \% \mathrm{CO}_{2}$ for 7 days to allow for proliferation. The medium was changed at 3 and 5 days. Harvested chondrocytes were then seeded into fibroin disks at a cell concentration of about $1.67 \times 10^{7}$ cells $/ \mathrm{mL}$. For the regeneration of cartilage, the fibroin sponge-chondrocyte constructs were cultured at $37^{\circ} \mathrm{C}$ in a humidified atmosphere of $95 \%$ air and $5 \%$ $\mathrm{CO}_{2}$ in DMEM supplemented with $10 \%(\mathrm{v} / \mathrm{v})$ FBS, $1 \%$ (v/v) antibiotic and $0.2 \mathrm{mM}$ ascorbic acid. The medium was changed every 2 days.

Friction tests were carried out at 7 and 14 days after the beginning of cultivation. The friction coefficients of fibroin disks which were seeded with no chondrocytes were also examined as a control group. Tissue engineered cartilage specimens were cut into $5.0 \mathrm{~mm}$ diameter disks for the friction test.

\subsection{Preparation of natural cartilage specimens}

Natural cartilage specimens were acquired from the femoral condyle of a 180 190 day-old Japanese pig (Aota chikusan, Kyoto, Japan). They were cut into $5.0 \mathrm{~mm}$ diameter cylinders and stored in saline solution until testing.

\subsection{Friction test}

A reciprocating-motion friction testing apparatus described previously [1] was used to measure the friction coefficients of tissue engineered cartilage and natural cartilage. Figure 1 shows a schematic drawing of the apparatus. The specimen was attached to the tip of the apparatus, pressed to the counter surface using an X-axis linear ball guide stage (Suruga-seiki Ltd., Shizuoka, Japan). A normal load was then applied to the specimen through the reaction force of the upper leaf spring, and the magnitude of the load measured with an eddy-current displacement sensor (Kaman Precision Products, Colorado, USA). A liquid vessel, containing saline solution, with the counter surface was then driven by a

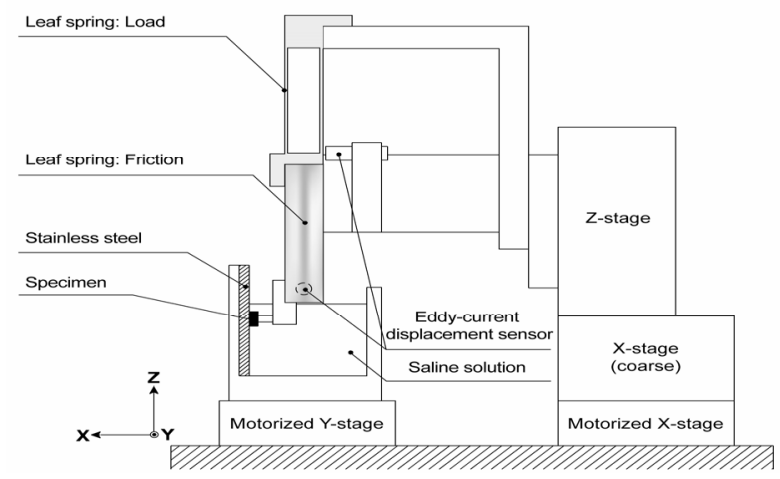

Figure 1: Schematic drawing of the friction test apparatus. 
Y-axis liner ball guide stage (Suruga-seiki) to produce a reciprocating motion. The deflection of the lower leaf spring was measured with an eddy-current displacement sensor (Kaman Precision Products) and used to calculate the friction force. A friction coefficient was then calculated from the measured normal load and friction force.

The friction test for natural cartilage was carried out under the following conditions. The applied pressure was $0.15 \mathrm{MPa}$ and the sliding velocities used were $0.008,0.08,0.8$ and $4 \mathrm{~mm} / \mathrm{s}$. Friction coefficients were recorded for 1 stroke after loading periods of $600 \mathrm{~s}$. Both the poly(MPC) grafted counter surface and the stainless steel surface were used as counter surfaces, and 3 specimens per sliding velocity were used for each counter surface.

The friction test for tissue engineered cartilage was carried out under the following conditions. The applied pressure was $0.15 \mathrm{MPa}$ and the sliding velocities used were $0.008,0.08,0.8$ and $4 \mathrm{~mm} / \mathrm{s}$. Friction coefficients were recorded for 1 stroke after loading periods of $600 \mathrm{~s}$. Only the poly(MPC) grafted counter surface was used as a counter surface, and 3 specimens per cultivation day were used for each sliding velocity.

\section{Results}

Figure 2 shows the relationship between sliding velocity and friction coefficient for natural cartilage as measured on both the poly(MPC) grafted and stainless steel counter surface. The friction coefficients measured on the stainless steel surface increased when the sliding velocity was lowered from $0.8 \mathrm{~mm} / \mathrm{s}$ to $0.08 \mathrm{~mm} / \mathrm{s}$. However, on the poly(MPC) grafted counter surface, the friction coefficients were lower than 0.01 at the sliding velocities of 0.08 and $0.008 \mathrm{~mm} / \mathrm{s}$.

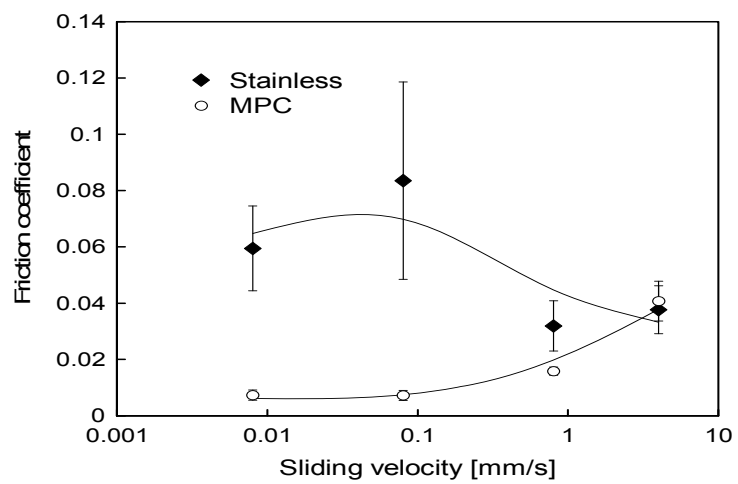

Figure 2: Friction coefficient-sliding velocity diagram for natural cartilage on the poly(MPC) grafted counter surface and stainless steel surface. Data represent mean $\pm \mathrm{SD}(\mathrm{n}=3)$. 
Figure 3 shows the relationship between sliding velocity and friction coefficient for tissue engineered cartilage cultivated for 7 and 14 days, as well as for the control specimen and natural cartilage measured on the poly(MPC) grafted counter surface. The friction coefficients for the control specimen were significantly higher than those for the tissue engineered cartilage and the natural cartilage at all sliding velocities. The friction coefficients for the tissue engineered cartilage cultivated for 7 and 14 days decreased when the sliding velocity was lowered from $4 \mathrm{~mm} / \mathrm{s}$ to $0.8 \mathrm{~mm} / \mathrm{s}$, and remained low even at low sliding velocities such as $0.08 \mathrm{~mm} / \mathrm{s}$ and $0.008 \mathrm{~mm} / \mathrm{s}$. However, the friction coefficients of the tissue engineered cartilage cultivated for 7 and 14 days were both higher than those for the natural cartilage at all sliding velocities.

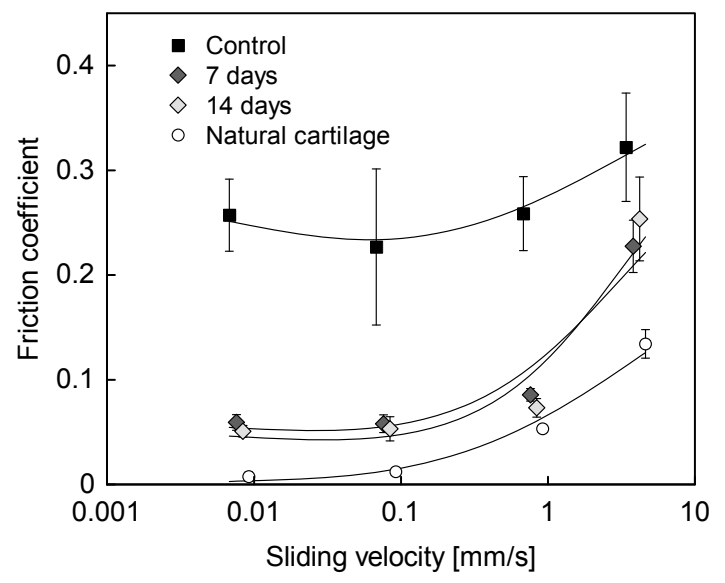

Figure 3: Friction coefficient-sliding velocity diagram for tissue engineered cartilage cultivated 7 and 14 days, natural cartilage and control specimen. Data represent mean $\pm \operatorname{SD}(n=3)$.

\section{Discussion}

Articular cartilage in vivo has a significantly low friction coefficient even at extremely low velocities. Additionally, the friction coefficient measured between cartilage and cartilage, which is the most vivo-like condition, is low [15-18]. However, in the cartilage-on-cartilage friction test, distortion resistance has a significant influence on friction force, so it is necessary to measure the friction coefficient using a flat counter surface in order to examine only surface frictional properties of cartilage. Many studies have measured the friction coefficient of articular cartilage on a metal or glass surface [19-21], but these values were significantly higher than reported in vivo measurements. This is partly because articular cartilage adheres to the surface of these materials. In this study, the results show that the friction coefficient of natural cartilage measured on a poly(MPC) grafted counter surface remains low even at the low sliding 
velocities. It is likely that the poly(MPC) grafted counter surfaces are able to prevent cartilage adhesion and maintain a fluid film between the articular cartilage and the counter surface even at low sliding velocities.

However, there is a possibility that the high frictional performance of the poly(MPC) grafted surfaces may mask changes resulting from cartilage maturation. The present study showed that the friction coefficient of tissue engineered cartilage decreased with cultivation time at low sliding velocities, which suggests that the proposed system was able to measure the tribological maturation of tissue engineered cartilage in a more natural lubricating environment.

\section{Conclusions}

In this paper, we propose a new method for evaluating the frictional maturation of tissue engineered cartilage in vitro. The poly(MPC) grafted flat surface was used as counter surface for a reciprocating motion friction test and the conclusions reached are as follows:

1. The friction coefficients of natural cartilage measured on the poly(MPC) grafted counter surface were lower than 0.01 at the sliding velocities of 0.08 and $0.008 \mathrm{~mm} / \mathrm{s}$, which is equivalent to that for natural cartilage-on-cartilage conditions.

2. The friction coefficients of tissue engineered cartilage at low sliding velocities decreased with cultivation period. It is suggested that the surface tribological maturation of tissue engineered cartilage can be measured by using the poly(MPC) grafted counter surface.

\section{Reference}

[1] Morita, Y., Tomita, N., Aoki, H., Sonobe, M., Wakitani, S., Tamada, Y., Suguro, T. and Ikeuchi, K., Frictional properties of regenerated cartilage in vitro, Journal of Biomechanics, 39, pp. 103-109, 2006.

[2] Katakai, D., Fujie, H., Nagai, K., Tamai, N., Myoui, A., Nakamura, N. and Yoshikawa, H., Compressive and frictional properties of repaired cartilage after subchondral bone implantation (Japanese), Japanese Journal of Clinical Biomechanics, 26, pp. 85-89, 2005.

[3] Morita, Y., Tomita, N., Aoki, H., Wakitani, S., Tamada, Y., Suguro, T. and Ikeuchi, K., Visco-elastic properties of cartilage tissue regenerated with fibroin-sponge, Biomedical Material Engineering, 12, pp. 291-298, 2002.

[4] Morita, Y., Tomita, N., Aoki, H., Wakitani, S., Tamada, Y., Suguro, T. and Ikeuchi, K., Evaluation of dynamic visco-elastic properties during cartilage regenerating process in vitro, Biomedical Material Engineering, 13, pp. 345-353,2003.

[5] Riesle, J., Hollander, A. P., Langer, R., Freed, L. E. and VunjakNovakovic, G., Collagen in tissue-engineered cartilage: types, structure, and crosslinks, Journal of Cellular Biochemistry, 71, pp. 313-327, 1998. 
[6] Vunjak-Novakovic, G., Martin, I., Obradovic, B., Treppo, S., Grodzinsky, A., Langer, R. and Freed, L. E., Bioreactor cultivation conditions modulate the composition and mechanical properties of tissue-engineered cartilage, Journal of Orthopaedic Research, 17, pp. 130-138, 1999.

[7] Ishihara, K., Ueda, T. and Nakabayashi, N., Preparation of phospholipid polymers and their properties as polymer hydrogel membranes, Polymer Journal, 22, pp. 355-360, 1990.

[8] Iwata, R., Suk-In, P., Hoven, P. V., Takahara, A., Akiyoshi, K. and Iwasaki, Y., Control of nanobiointerfaces generated from well-defined biomimetic polymer brushed for protein and cell manipulations, Biomacromolecules, 5, pp. 2308-2314, 2004.

[9] Matyjaszewski, K., Miller, P., Shukla, N., Immaraporn, B., Gelman, A., Luokala, B. B., Siclovan, T. M., Kickelbick, G., Vallant, T., Hoffmann, H. and Pakula, T., Polymers at interfaces: using atom transfer radical polymerization in the controlled growth of homopolymers and block copolymers from silicon surfaces in the absence of untethered sacrificial initiator, Macromolecules, 32, pp. 8716-8724, 1999.

[10] Aoki, H., Tomita, N., Morita, Y., Hattori, K., Harada, Y., Sonobe, M., Wakitani, S. and Tamada, Y., Culture of chondrocytes in fibroin-hydrogel sponge, Biomedical Material Engineering, 13, pp. 309-316, 2003.

[11] Chueh, S., Tomita, N., Yamamoto, K., Harada, Y., Nakajima, M., Terano, T. and Tamada, Y., Transplantation of allogeneic chondrocytes cultured in fibroin sponge and stirring chamber to promote cartilage regeneration, Tissue Engineering, 13, pp. 483-492, 2007.

[12] Tamada, Y., New process to form a silk fibroin porous 3-D structure, Biomacromolecules, 5, pp. 217-228, 2005.

[13] Kambe, Y., Yamamoto, K., Kojima, K., Tamada, Y. and Tomita, N., Effects of RGDS sequence genetically interfused in the silk fibroin light chain protein on chondrocyte adhesion and cartilage synthesis, Biomaterials, 31, pp. 7503-7511, 2010.

[14] Yamamoto, K., Tomita, N., Fukuda, Y., Suzuki, S., Igarashi, N., Suguro, T. and Tamada, Y., Time-dependent changes in adhesive force between chondrocytes and silk fibroin substrate, Biomaterials, 28, pp. 1838-1846, 2007.

[15] Ikeuchi, K., Shibata, N., Arimoto, M. and Tomita, N., Friction between articular cartilage and meniscus in the knee joint (Japanese), Japanese Journal of Clinical Biomechanics, 15, pp. 183-186, 1994.

[16] Mabuchi, K., Tsukamoto, Y., Obara, T. and Yamaguchi, T., The effect of additive hyaluronic acid on animal joints with experimentally reduced lubricating ability, Journal of Biomedical Materials Research, 27, pp. 865870, 1994.

[17] Katta, J., Stapleton, T., Ingham, E., Jin, M. Z. and Fisher, J., The effect of glycosaminoglycan depletion on the friction and deformation of articular cartilage, Journal of Engineering in Medicine, 222, pp. 1-11, 2007. 
[18] Prisca, N., Bernard C., Jacqueline L. B., Adrien M., Jean M. D. and Didier S., An equine joint friction test model using a cartilage-on-cartilage arrangement, The Veterinary Journal, 183, pp. 148-152, 2010.

[19] Pickard, E. J., Fisher, J., Ingham, E. and Egan, J., Investigation into the effects of proteins and lipids on the frictional properties of articular cartilage, Biomaterials, 19, pp. 1807-1812, 1998.

[20] Murakami, T., Sawae, Y. and Ihara, M., Protective mechanism of articular cartilage to severe loading: roles of lubricants, cartilage surface layer, extracellular matrix and chondrocyte, JEME International Journal, 46, pp. 594-603, 2003.

[21] Forster, H. and Fisher, J., The influence of continuous sliding and subsequent surface wear on the friction of articular cartilage, Journal of Engineering in Medicine, 213, pp. 329-345, 1999. 